\title{
A question of great impact
}

\section{John F. Kerridge}

Coon Mountain Controversies: Meteor Crater and the Development of Impact Theory. By William Graves Hoyt. University of Arizona Press: 1987. Pp.442. \$40, £34.50.* Meteorite Craters. By Kathleen Mark. University of Arizona Press: 1987. Pp.288. $\$ 29.95, £ 24.50$.*

TrACING the evolution of meteorite impact theory affords us several insights into why scientific progress can prove at times to be so painfully slow. Thus, we can observe dogma characteristically defying logic: "[Impact theory] is based on assumptions which have no support either from what we see going on around us or from anything which history or scientific investigation tells us has happened in the past". The boundaries erected between disciplines are seen interfering with the flow of information: "But why there are not more [impact craters on the Earth], or at least some evidence of their remains

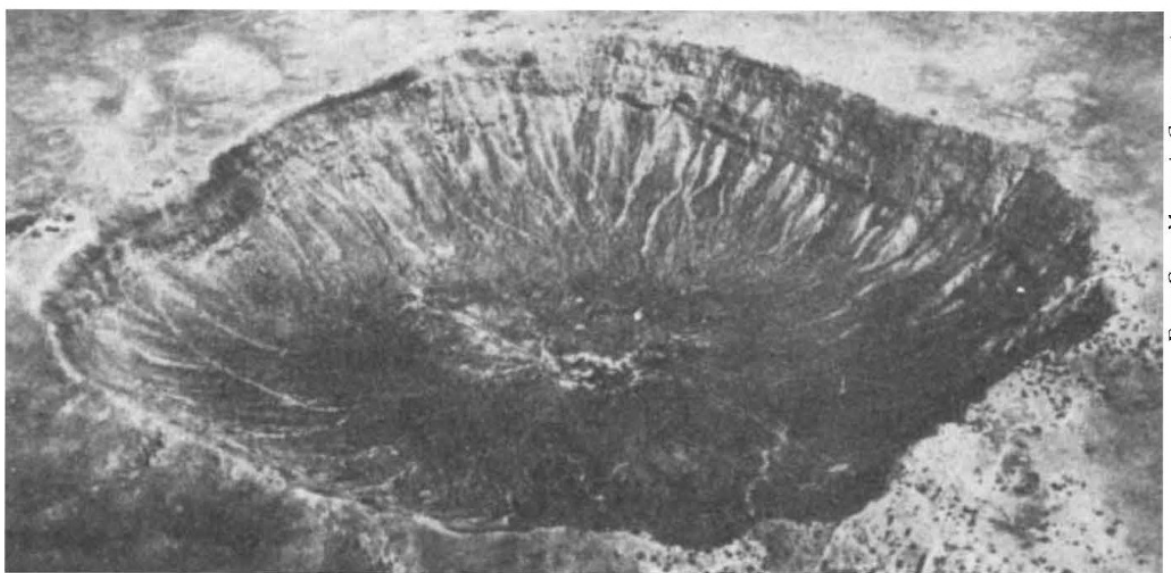

A hell of a big hole - Meteor Crater in Arizona, over $1 \mathrm{~km}$ in diameter

has not been explained", according to an astronomer in 1919. We are reminded once again of the perils of failing to quantify the quantifiable: "It's a hell of a big hole and it was made by a hell of a big thing", compared with ". . . the mass [of the Canyon Diablo meteorite] cannot have exceeded $3,000,000$ tons and may well have been of the order of 100,000 tons". And we can feel across the years the force of a confident assertion: "It is certain that no explosive theory could produce the terraces such as we see in [the lunar crater] Copernicus".

Those quotations can be found in Coon Mountain Controversies, the more academically orientated of two recent books on the development of impact theory, both emanating, remarkably enough, from the same publisher. In fact, although there is considerable overlap of material between the books, they differ so markedly in scope, depth of detail and level of presentation, that their readerships are unlikely to overlap to the same *In Britain available from Eurospan, 3 Henrietta Street, London WC2E 8LU. extent. Although Mark aims for a global, indeed Solar-System-wide, and nontechnical overview of the emergence, growth and consolidation of impact theory, the focus of Hoyt's book, as its title implies, is on the wealth of scientific, historical and even financial detail concerning Meteor Crater, formerly known as Coon Mountain, and its indefatigable explorer from 1903 to 1929 , Daniel Moreau Barringer.

The plural in Hoyt's title is important. For him, as for Barringer, the struggle to prove the impact origin of Meteor Crater was only part of the story; the attempt to

prove its value as a mineral resource was an even more dramatic and, in Barringer's case tragic, affair. In practice, the two controversies (impact versus endogenic origin, and large, slow bolide versus small, fast one) had rather little in common. However, both hinged, to a certain extent, on the interpretation of a wellknown feature of impact craters, most noticeable on the Moon, namely their circularity. It is instructive to examine Barringer's approach to this issue.

Until about the time of the First World War, for most scientists, geologists and astronomers alike, the circularity of virtually all lunar craters represented one of the main obstacles to acceptance of an impact theory for their origin. Most meteoroid impacts on the lunar surface being oblique, it was believed that the resulting craters would have been predominately elliptical. Even G.K. Gilbert, a figure whose almost mythical shadow falls heavily, though enigmatically, across the pages of Hoyt's book, felt it necessary to invoke a cockamamy swarm of providentially located "moonlets" to supply

the vertical impact trajectories apparently required. For Barringer, a lifetime's familiarity with high-powered hunting rifles provided an adequate analogy: the "splashing distribution of ejected material" from a shot into "stiffish mud" led to a round crater, even at an incident angle of $45^{\circ}$.

That analogy sufficed for Barringer during the first controversy but it let him down badly when the debate turned to the mass of projectile remaining beneath Meteor Crater, a quantity of vital importance to his future mining fortunes. It turns out that the physics involved in the excavation of hypervelocity-impact craters is far too complex to be handled by simple argument-by-analogy. Lacking, in common with virtually all other scientists of the time, an understanding of that phy sics, and resistant to the idea of a process that would have vaporized or disintegrated his precious ore, Barringer failed to recognize the literally explosive significance of circularity so that he grossly overestimated the mass of residual meteoric material. The bullet had, in fact, vanished from the target.

Hoyt blends the scientific issues, the commercial and legal factors, and the personalities involved into a sure-footed narrative that never fails to hold the reader's interest. As a chapter in the history of science, it is of considerable,

\section{Copies of articles from this publication are now available from the UMI Article Clearinghouse.}

Yes! I would like to know more about UMI Article Clearinghouse. I am interested in electronic ordering through the following system(s)

7 DLALOG/Dialorder $\quad \exists$ ITT Dialcom

Dityme

$\square$ Other (please specify

$\square$ lam interested in sending my order by mail

[] Please send me your current catalog and user instruc. tions for the system(s) I checked above.

Name

Title

Institution/Company

Department

Address

City

Phone (

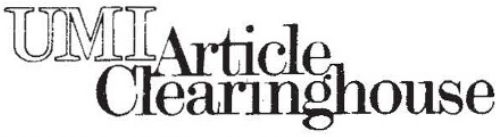

Mail to: University Microfilms International

300 North Zeeb Road, Box 91 Ann Arbor, Ml 48106 
and probably lasting, value; it is difficult to imagine a more carefully documented and sensibly reasoned account of the way in which ideas on impact theory evolved during the era covered by the book. If it has a failing it is that there is little attempt to put the issue of the acceptance of impact theory into a broader philosophical context. For example, was the opposition on the part of traditional geologists inherited from Lyell, or was it more a reaction to ideas arising outside the mainstream of science?

Compared with Hoyt, Kathleen Mark paints on a much broader canvas, paying more attention to the controversy surrounding "cryptovolcanic" structures, to the increasingly sophisticated study of the erosional pathology of impact craters, and to the continuing search for physical criteria for an impact origin and the structures with which they are associated. To render such material at an avowedly non-technical level is an ambitious undertaking but in this case it has been

\section{Light industry}

\section{John N. Howard}

Land's Polaroid: A Company and the Man Who Invented It. By Peter C. Wensberg. Houghton Mifflin: 1987. Pp.258. \$18.95.

EDWIN Land was born in Connecticut in 1909. Even as a youth he had decided he would achieve fame and fortune in the world of science and technology. After all, had not Thomas Edison, Henry Ford, Alexander Graham Bell and George Eastman - all self-made men, and all then still alive - succeeded by developing practical, usable technology?

When he was 17 his parents sent him to Harvard to study physics. Before the first year was over he had already picked a likely area for a scientific breakthrough: polarized light. Unfortunately he could not immediately see any important practical application. Then, on a vacation trip to New York City he walked into Times Square, saw the bright lights and the glare of automobile headlights, and recognized the need, the opportunity - suppose automobiles had headlights emitting light in one plane of polarization, and windshields of the crossed plane; then, forward vision at night should be unimpaired, but dangerous glare from oncoming headlights would be filtered out. successful. The author handles the basic scientific concepts with confidence and describes them with clarity. Many students, nominally more advanced than the audience for which the book is designed, will nonetheless find it instructive

Both books do justice, in their different ways, to the field of impact theory. Both authors handle observations and ideas with aplomb, but it's probably fair to say that their accounts also tend to neglect the contributions of experimental science. For example, the hypervelocity-impact experiments so beautifully designed and executed by Don Gault surely deserved more than just a footnote mentioning their reproduction of shatter cones. Such carping aside, however, these are excellent books; one or other of them should meet the needs of almost anyone wishing to learn, or learn more, about the history of impact theory.

John F. Kerridge is at the Institute of Geophysics and Planetary Physics, University of California, Los Angeles, California 90024, USA.

Land dropped out of college, took a room in New York, and spent every day at the library reading every published paper about polarized light. An earlier researcher, William Herapath, had found that tiny crystals of iodoquinine sulphate strongly polarized light, but Herapath had been unable to grow them large enough to be useful. Land repeated some of these experiments and determined that he could make the needle-like crystals line up in a magnetic field. Perhaps he could then press them into a sheet of film.

$\mathrm{He}$ went back to Harvard to better laboratory facilities, but just short of graduation dropped out again, this time (with a physics colleague) forming a small company to make polarizing film, which they named Polaroid. By 1935 he had orders from Eastman Kodak for polarizing filters for cameras. Then the American Optical Company introduced Polaroid sunglasses. The business grew, incorporated in 1937 as the Polaroid Corporation, and during the war engaged in defence research and became a successful small company. But the big money of polarized automobile headlights did not materialize: the industry feared that filters on headlights would make them dim.

For Land, the big breakthrough occurred in late 1943, while he was vacationing with his family in New Mexico. He took some pictures of his three-year-old daughter Jennifer and she wanted to see them right away. "They're not ready", he said. She replied, "Why can't I see them now?". Land went for a walk, and within an hour he had in mind the entire process of what needed to be done to make selfdeveloping photographic film possible. The new process of "instant photography", with a working model of the camera, was demonstrated at the February 1947 meeting of the Optical Society of America, and the camera became an instant commercial success.

The company grew and prospered; in 1963 colour film for Land cameras was introduced and in 1972 Polaroid introduced the very sophisticated SX-70 camera, with automatic focusing, automatic aperture for correct exposure and a self-developing print. Through all of the expansion of the company - from a halfdozen employees to as many as $20,000-$ Land remained completely in charge: chairman, president, chief executive officer and chief scientist. Starting in 1975 ,

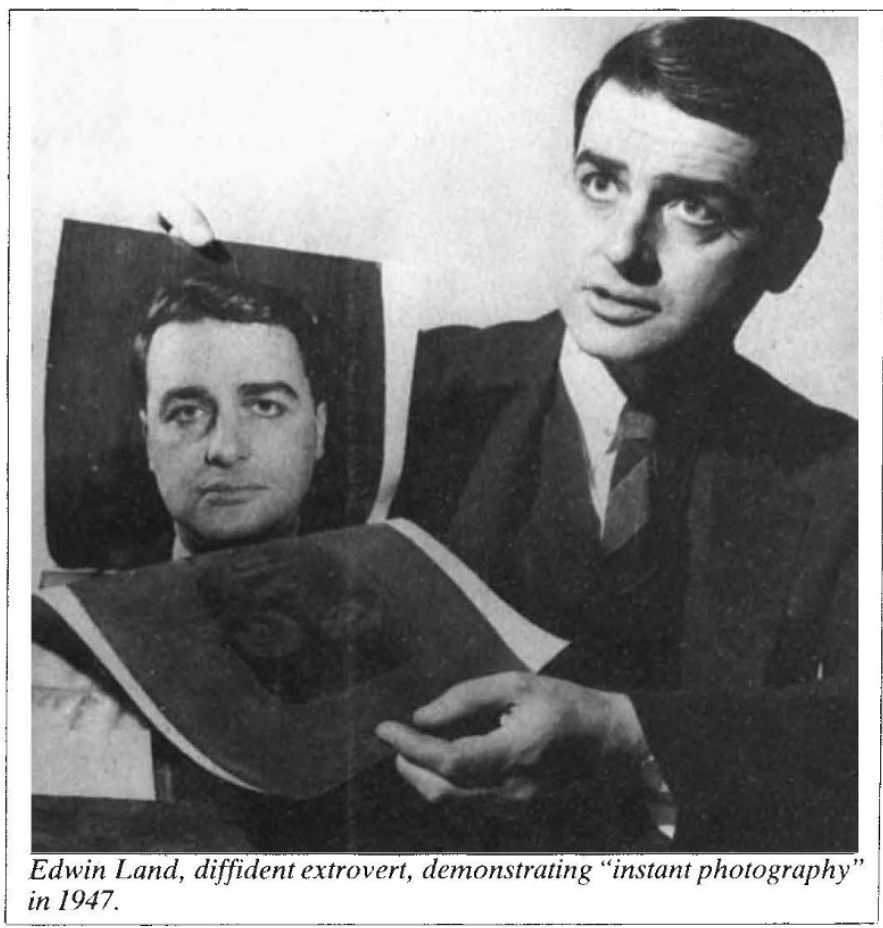
he gradually relinquished these posts, and retired from Polaroid in 1982 at age 73 .

Land is an inventor; his name appears on 533 US patents, second only to Thomas Edison's 1,093. But whereas there are 23 biographies of Edison in print, Wensberg's book is only the second sketch of Land. The book is unauthorized, but it is not by an outsider; Wensberg worked at Polaroid for 24 years, the last several of them as executive vice president. When he told Land he was writing a book about Land and Polaroid, Land said, "That's very disturbing, Peter. Why would anyone want to read such a book?". Wensberg replied, "There's a tremendous interest now in entrepreneurship". "Isn't that an awful word", was the response, "It reminds one of a man standing behind a 